University of Nebraska - Lincoln

DigitalCommons@University of Nebraska - Lincoln

$11-1-2006$

\title{
Measuring the development of executive control with the Shape School
}

\author{
K. A. Espy \\ University of Nebraska-Lincoln, kespy2@unl.edu
}

R. B. Bull

J Martin

W. Stroup

University of Nebraska-Lincoln, wstroup1@unl.edu

Follow this and additional works at: https://digitalcommons.unl.edu/dcnlfacpub

Part of the Neurosciences Commons

Espy, K. A.; Bull, R. B.; Martin, J; and Stroup, W., "Measuring the development of executive control with the Shape School" (2006). Developmental Cognitive Neuroscience Laboratory - Faculty and Staff

Publications. 2.

https://digitalcommons.unl.edu/dcnlfacpub/2

This Article is brought to you for free and open access by the Developmental Cognitive Neuroscience Laboratory at DigitalCommons@University of Nebraska - Lincoln. It has been accepted for inclusion in Developmental Cognitive Neuroscience Laboratory - Faculty and Staff Publications by an authorized administrator of DigitalCommons@University of Nebraska - Lincoln. 


\title{
Measuring the Development of Executive Control With the Shape School
}

\author{
Kimberly Andrews Espy \\ University of Nebraska-Lincoln
}

Jessica Martin

Southern Illinois University School of Medicine

\author{
Rebecca Bull \\ University of Aberdeen
}

Walter Stroup

University of Nebraska-Lincoln

\begin{abstract}
Although several neurodevelopmental and psychiatric disorders can emerge during the preschool period. there are comparatively few instruments to aisess executive control. Evidence for validity of the Shape School (K. A. Espy, 1997) was examined in a sample of 219 typically developing young children. There was good evidence for validity, as Shape School performance variables were interrelated and were associuted to other criterion measures considered to measure aspects of executive control. Also suggesting validity, the Shape School variables varied as a function of whether the task demands (a) were exccutive, (b) required inhibition of a prepotent response or context-controllecd seicction among relevant stimulus-response sets, and (c) included unitary or concurrent processing. The Shape School may be an effective tool by which to measure executive control in young children who have atypical developmental patterns.
\end{abstract}

Keywords: executive function, cognitive assessment, preschoolers, hierarchical linear modeling

Despite widespread recognition that executive control develops significantly during the preschool years; plays a central role in cognition, academic learning, and social behavior (e.g., Bull, Johnston, \& Roy, 1999: Desimone \& Duncan, 1995: Espy, McDiarmid, Cwik, Senn, Hamby, \& Stalets, 2004; Gathercole \& Pickering, 2000; Hughes, 1998b; Hughes, White, Sharpen, \& Dunn, 2000; Isquith, Gioia, \& Espy, 2004); and is affected in those who have diverse clinical disorders (c.g., Anderson, Anderson, Grimwood, \& Nolan, 2004; Espy, Kaufmann, \& Glisky, 1999; Espy et al., 2002; Ëwing-Cobbs, Prasad, Landry, Kramer, \& DeLeon, 2004: Pennington \& Ozonoff, 1996), therc are few validated instruments available to measure these abilities. Young children have a more limiled knowledge base, arc lcss verbally proficient, are more impulsive, and have more difficulty attending, factors that constrain their performance on complex executive tasks. Thus,

Kimberly Andrews Espy, Office of Rescarch \& Graduate Studies and the Department of Psychology, University of Nebraska-Lincoln; Rebecea Bull, School of Psycholory, University of Aberdeen, Aberdcen, Scotland; Jessica Martin, Department of Family \& Community Medicine, Southern Illinois University Schmol of Medicine; Walter Stroup, Department of Statistics, University of Nebraskid-Lincoln.

This research was supported in past by National Institute of Mental Health Grant 1R01 MH065668, National Institute on Drug Abuse Grant IR0I DA014661, and National Institute of Child Health and Development Grant SP01 HD038051-06 to Kimberley Andrews Espy, and grants from the Carnegie Trust and British Academy to Rebecca Bull. We thank the participating families, undergraduates, medical students, project staff, and graduate students who assisted in various laboratory tasks associated with this study.

$$
\text { and }
$$

Correspondence concerning this aticle thould be addressed to Kimberty Andrews Espy. Associate Vice Chancellor for Research, 303 Canfield Administration Building, University of Nebraska-Lincoln, Lincoln, NE 68688-0433. E-mail: kespy2@unl.edu moxlem etforts have focused on careful design of developmentally appropriate tasks that engage young children in order to better capture their executive abilities.

Although there are many different models of executive control, the most prominent in pediatric clinical neuropsychology include a fractionated-ability structure of working memory, inhibitory control, and adaptive shifting/rule-govemed behavior (e.g., Anderson, 1998; Levin et al., 1996; Welșh, Pennington, \& Groisser, 1991). What the vatious accounts differ in is the relative weights ascribed to these executive constructs and when or how they are combined, whether they are differentially localized within the brain. and when or how they develop during childhood. In contrast, recent studies in developmental cognitive neuroscience have manipulated specific task demands (e.g., inereasing working memory load, decreasing inhibitory demands) to characterize executive control organization (e.g., Diamond, Briand, Fossella, \& Gehlbach, 2004; Espy, 1997; Zelazo. Mueller, Fryc, \& Marcovitch, 2003),

Regardless of the executive control model utiliyed, studies of normative executive control in preschool childretn use several paradigms: (a) rule-governed, attribule-based sorting tasks (e.g., Espy, Kaufmann, MeDiarmid, \& Glisky. 1999; Hughes, 1998a; Dimensional Change Card Sort [DCCS], as discussed in Zelazo. Frye, \& Rapus, 1996): (b) manual selection or verbal naming of stimuli that conflict or interfere on the basis of natural associations (e.g., Carlson \& Moscs, 2001: Diamond, Kirkham, \& Amso, 2002; Wright, Waterman, Prescott, \& Murdoch-Eaton, 2003); and (c) manual scarch tasks that impose working memory demands (c.g.: Diamond Prevor, Callender \& Druin, 1997, Espy, Kaufmann, Glisky, \& McDiamid, 2001 Hughes, 1998 ) or inhibiting pepotent or prohibited somatic motor responses (c.s. Carlgon \& Moses, 2001; Espy, Kaufmain, McDiarmid, \& Glisky, 1999 ; Kochaniska. Murray, Jacques, Koenig, \& Vandegeest, 1996; Reed, Pien, \& 
Rothbart, 1984). Notc that these tasks vary along several dimensions.

The first of these dimensions is the type of inhibition required. In some tasks, the child must suppress somatic motor responses, for example, by remaining still whilc the examiner ties to distract him or her. In others, inhibition is more "cognitive"; that is, an internally represented rule or responsc set that had been previously active must be discngaged subsequently and controlled if the child is to engage and implement another responsc. Fricdman and Miyake (2004) found evidence for this distinction using structural equation modeling to parse nomative adult performance on those tasks that requirc inhibiting a prepotent response or resisting interference from distraction that is irrelevant to the current task from those involved in resistance to proactive interference from a previously active rule or response set. However, Diamond reccntly has argued that a common mcchanism, "attentional incria," underlies the classic dysexecutive behavior that young children display across lasks (Kirkham, Cruess, \& Diamond, 2003). In an argument akin to the "task-set inertia" concept from the adult cognitive litcrature (c.g., Allport, Styles, \& Hsieh, 1994), she states that perfomance is disrupted when the young child's attention gets pulled away from the response set at hand by conflicting stimulus propertics, thereby leading to the classic dissociation between knowledge and action. Inhibition resolves the conflicts among stimulus properties, response mappings, and current context demands, allowing the child to select and activate one rule or rcsponse in one context, then cognitively discngage when the context changes, and in tum select another competing but nowrelevant response or set (Miller \& Cohen, 2001). In these studies, in which inhibition can be described as context-controlled selection, a manual response often is the responsc method (e.g, button press), but it is not itself a target of inhibition per se. It rcmains to be determincd empirically how "attentional incria" might operate in the intentional suppression of a somatic motor response, or whether in fact these two inhibitory processes are distinguishable in young children (Bishop, Aumodt-Ieaper, Creswell, McGurk, \& Skuse, 2001; Nigg. 2000).

Second, the nature of the conflict varies. In tasks requiring suppression of executive motor response, conflict often is with a prohibited action or previously rewarded response. In "DayNight" (Gerstadt, Hong, Diamond, 1994), Luria's Tapping task (Diamond \& Taylor, 1996), and Dots (Diamond ct al., 2004), the executivc demands require a responsc that is counter to the "natural" stimulus-responsc mapping that is built from the everyday sensory, motor, and linguistic environment (e.g., saying "night" to a picture of the sun in the sky). In contrast, the DCCS utilizes conflict betwecn the simuli properties and the required response, but the conflict between the two dimensions is arbitrary (e.g., color is not inhercntly related to shape), Conflict demands appear critical to invoking executive control, as some postulate that it is the conflict betwecn stimulus-response mappings and new reward contingencies that drives prefrontal activation (e.g.. Milicr, 2000; O'Reilly, Noelle, Braver, \& Cohen, 2002). For cxample, 3-yearolds can sort the conflicling cards successfully when the second dimension is not present (Brooks, Hanauer, Padowska, \& Rosman, 2003) or is irrclcvant to sorting (Perner \& Lang, 2002; Rennie, Bull, \& Diamond, 2(04), or when the response is not canonically related (Diamond et al., 2002).
The demands on working memory and short-term storage also vary: with tasks such as Six Boxes (Diamond et al. 1997) and Nósy Book (Hughes, $1998 \mathrm{a}$ ) involving significant storage demands, wheregs others, including various delay tasks' (e.g., Carlson 2 Moses, 2001; Kochanska et al., 1996), appear to require little information to be retained online to guide subsequent performance,

Finally, most exccutive tasks for preschoolers developed to date are nonverbal-man advantage for assessing young preschool children with less mature verbal skills. However, given the rapid increasc in verbal proficiency in this age range, and the importance of executive skills in the more verbally laden academic context in the transition to formal schooling, it would be useful to have tools to assess individual variances in executive abilities that utilize verbal material. Perfomance on such tasks may be more highly related to outcomes of interest that load heavily on verbal skills, such as reading and mathematics.

Because a central interest in the cognitive developmental literature has been to characterize at what age a child "passes" or "fails" a given task, the sensitivity of many experimental tasks is restricted to a narrow age range. Such lasks are not well suited to clinical use in evaluating children of varying ages. Furthermorc, basic psychometric properties, such as reliability and validity, have not been studied, a process eritical in the clinical context where "high stakes" judgments about individual children are made. Determining reliability for executive tasks is complicated, however. as novelty, salience, and difficulty play important roles in invoking executive control, both on cognitive (e.g., O'Reilly et al., 2002) and newral levels (e.g., Barch et al., 1997; Cascy et al., 2001). The purpose of this study, then, was to investigate cvidence for validily of a newly devcloped measure of executive control, the Shape School (Espy, 1997), in a large, divcrse sample of young children, first by examining internal association and variable interrelations. then by investigating predictive associations with other commertcially available, validatcd cxccutive tasks, and finally by detemining task sensitivity to differing executive demands and to individual background charactcristics.

\section{Method}

\section{Participants}

The sample was composed of 219 typically developing children who ranged in age from 3 years 6 months to 6 years 1 month $(M=4.82$ ycars, $S D=0.50$ years). There were 119 girls $(54 \%)$ and 100 boys. Consistent with the demographics of the local area, $85 \%(n=187)$ of the sample was Caucasian. Of those of minority race/ethnicity, 22 children wеre African American, 8 were Asian, and 2 wcre of mixed race. None of these children were diagnosed with any neurological, psychiatric, or developmental disorders, determined on the basis of parental report. Children varied with respect to vocabulary skills (assessed by either the available Picture Vo cabulary subtest from the Woodcock-Johnson Psycho-Eduçational Battery-Revised (WJ-R; Woodcock \& Johnson, 1989; $n=112$ ) or the Vocabulary subtest from the Wechsler Preschool and Primary Scale of Intelligence-Revised (WPPSI-R; Wechsler, 1990; $n=113$ ). Both of these tasks assess vocabulary. In the WPPSI-R, items progress from picture identification to definition of word meaning. The $W J-R$ is composed entirely of picture identification ifems. The average standard score was $106.22(S D=12.90)$. As there was no difference in the standard scores derived from these two instruments, $F(1,213)=0.06, p=80$, and the instruments utilize the same metric (expected mean and standard deviation). scores werc pooled for the purposes of investigation of individual differences in performance. 


\section{Materials}

Shape School. The Shape School (Espy, 1997) is designed to assess difterent aspects of execulive control in young children using colorful, affectively enguging stimuli presented in an age-appropriate and appealing format, a storybook. The story has four parts, which constitute Conditions A, B, C. and D. Each child participates in all four conditions and always in the same fixed order. The story begins by setting up the premise, showing stimulus figures (colored squares and circles with cartoon faces, arms, and legs) playing on a playground. After being introduced to one class of children, whose "names" are their colors, the child names each stimulus figure color, which allows the test conductor to assess whether the child can reliably recognize and name the colors. As the story continues, the child is told that the story figures are lining up to go into the play yard. In this control condition, Condition $A$, the child names the color of each of the figures, which are arranged in three lines of five across the page. This condition serves two purposes, to measure baseline naming specd and, more important, to establish the relation between stimulus propertics (color) and response (naming stimulus color). The fact that conflicting shape information is present in each stimulus but is not yet identified as relevant enables direct condition comparisons.

In Condition B, the story line continues with it being lunchtime, where not ail of the figures have finished their work. "Happy" and "sad/ frustrated" expressions are added to the faces of the stimulus figures to depic those who have completed their work and those who have not. respectively. The child is instructed to call the names of the figures who have finished their work to proceed to lunch and not to call the names of those who are not ready. In the same contiguration of three rows of five figures each, there are nine happy-faced stimuli requiring the color-naming response and six sud/frustrated-faced stimuli requiring responsc suppression,

A second classroom is introduced in Condition $C$, in which the stimulus figures wear hats. The child is instructed that the names of the hatted pupils are the figure shapes and that the names of the hatless pupils remain the stimulus tigure colors, After practice with six stimulus figures, the child is told that the figures are in line to go to storytime; the child then names the shapes of the figures with hats and colors of the hatless figures in the three row by five figure configuration. There are eight figures without hats and seven with hats interspersed randomly, and the child must switch between naming hatted figure color and hatless figure shape as cued, respectively. Finally, in Condition D, the "happy" and "sad" expressions are reintroduced for both hatted and hatless figures, with the child instructed that not all figures are ready to participate in art. The child has to conçurently suppress naming the "sad/frustrated" figures (hatted and hatless), name the shapes of the hatted, happy-faced figures, and name the colors of the hatless, happy-faced figures. There are five halless, happy-faced figures; three hatted, happy-faced figures; threc hatted, sad-faced figures; and four hulless, sad-faced figures, aguin interspersed across the three row by five figure array. A summary description of the Shape School tasks and the hypothessized demands is in Table 1.

In all conditions, children are not allowed to procecd to the test page array unless they have named the characters successfully on the practice page, a step taken to ensure adequate rule knowledge prior to application. The experimenter records the number of stimuli correctly identified according to the pertinent rule (accuracy) and the timc to complete naming the pertinent stimuli in the array (latency) for each of the conditions. A simple stopwitch is used to record latency for the child to name all relevant stinuli on the page.

Statue. Statue is an allention/executive function NEPSY subtest (Korkman, Kirk, \& Kemp, 1998). The child stands in a set position (i.e., with eyes closed, without body movements or vocalizations) pretending to hold a flag for a 75-s period. $\Lambda t$ set intervals, the examiner coughs, knocks on the table. drops a pencil, or suys "Ho Hum!" as a discraction to induce the child to breuk the still posture. For ench 5-s epoch, the child is awarded 2 points if there is no inappropriate response (i.e., the eyes are kept shut and there is no body movement or vocalization), 1 point if there is one inappropriatc response, and 0 points if there is more than onc inappropriate responsc, with a muximum score of 30 . The reported NEPSY Statue

Table 1

Summary of Shape School Conditions.

\begin{tabular}{|c|c|}
\hline Condition and tusk description & Hypothesized demands \\
\hline \multicolumn{2}{|l|}{ A } \\
\hline Name figure colors & $\begin{array}{l}\text { Maintain S-R rules online } \\
\text { Attend to relevant attributes } \\
\text { Access semantic stores } \\
\text { Expressive naming }\end{array}$ \\
\hline 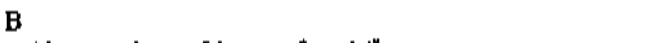 & \\
\hline $\begin{array}{l}\text { Name colors of happy-faced tigures } \\
\text { Inhibit naming of sad/frustrated-faced figures }\end{array}$ & $\begin{array}{l}\text { Maintain S-R rules online } \\
\text { Attend to relevant attributes } \\
\text { Access semantic stores } \\
\text { Response suppression } \\
\text { Expressive numing }\end{array}$ \\
\hline $\begin{array}{l}\text { C Narte colors of hatless figures } \\
\text { Name shapes of hatted figures }\end{array}$ & $\begin{array}{l}\text { Maintain S-R nules online } \\
\text { Attend to relevant attributes } \\
\text { Access semantic stores } \\
\text { Context-controlled selection } \\
\text { Expressive naming }\end{array}$ \\
\hline 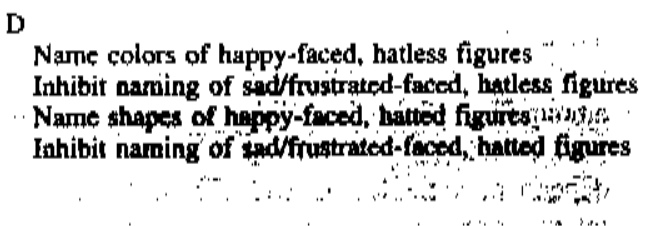 & 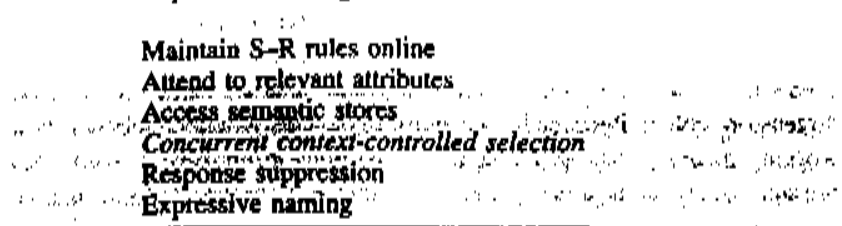 \\
\hline
\end{tabular}

Note, $\mathbf{S}-\mathbf{R}=$ stimulus-response, Unique demands are noted in italics. 
test-retest comelation is .50 in 3- to 4-year-olds and .75 in 5- and 6-year-olds.

iVisual Anenrion (VA). In this second attention/executive function NEPS $X$ rubes the child is instructed to find the jtems that maich the target stimuli among a page of tagets and distractors. In the standard NEPSY administration, VA includes different arrays for children ages 3 and 4 years versus those ages 5 years und above. Onty the random cat array is common to both age groups. Therefore, for the purposes of this sudy, the number of targets (maximum 20 cats) correctly identified and completion time (maximum $180 \mathrm{~s}$ ) from the random cat aray only were scored to enable comparison across the full age spectrum. The reported test-retcst reliability for VA was .69 in 3- and 4-year-olds and .71 in 5- and 6-year-olds.

Digir Span. After an initial practice session, a standard sequence of digits is presented auditorily, starting from a span length of two. Euch child is required to recall the digit strings in the order of presentution, with a maximum of two trials at each string length, Maximum digit span length is recorded. The reported reliability cocfticients for all ages exceeded 0.85 (Elliot, 1990).

\section{Procedure}

A truined child-clinical graduate student blind to the experimental hypotheses administered the Shape School and the criterion tests to preschool children in a single session. The children were assessed individually in a quiet roorn, with the parent or guardian present (completing study forms). Short breaks were uscd when necessary to muintain cooperation and interest. Parents were compensated for study participation, and the children received a bag of developmentally appropriate toys, stickers, and other small items.

\section{Design}

Evidence for validity was examined first by considering internal association (Cronbach's ulpha) and the pattern of intra- and intercondition correlations among the Shape School variables. Predictive validity was considered by compuring the relations betwęn pertommance on the Shape School and perfomance on standardized tests specifically considered to measure cxccutive shilities in this age range, namely NEPSY Attention/ Executive Function Domain subtests and Digit Span. These standardized tasks were chosen as a "first pass" to establish evidence for predictive validity of the Shape School because (a) they have known psychomeric properties and (b) they are commercially available to clinicians and researchers, thereby providing a shared, widespread basis for evaluation and compsrison (e.g., Friedman \& Miyake, 2004). Furthermore, all criterion measures provide a distributed range of scores that better captures the range of executive skills among young children, unlike the nonstandardized, experimental DCCS, which is scored on a puss-fail basis.

Finally, evidence for validity was investigated by determining whether Shape School performance differced by cxecutive task demands and individual differences in child characteristics. In Condition A, basic psychomotor naming speed of simple stimulus-response mappings can be disumbiguated from the additional executive ubilities utilized in Conditions $B, C$, and $D$. Therefore. evidence for validity was supported if performance differed between the control condition, $A$, and the executive conditions, $B$, $\mathrm{C}$, and $\mathrm{D}$. In Condition $\mathrm{B}$, a cue is provided to indicate wlen the child should suppress the color'naming response. Then in Condition $C$, the child must utilize the second conflicting dimension (shape) to name the relevant cucd stimuli, which ure intermixed with stimuli that are named by the first dimension (color). Becausc both conditions include (a) a relatively constant working memory lond of maintaining two rules in mind with overt ceses present that sigmal the correct stimulus-response mupping and (b) proactive interference from the same previously active response set. we believed condition-related performance differences would shed light on the nature of inhibitory processes. Evidence for validity was provided if performance differed between Condition B (response suppression) and Condition C (coptext-controlled selection). Finally, complexity; whether at the level of 14) pimulux (Brooks et al, 2003; Perner \& Lang, 2002), response (Rennic ed al, 2004), or stimulus-response mapping rule (Zelazo et al., 2003). affects executive task performance. At the most basic level, complexity can be operationalized as performing a task with uniquely specific demands in a single block, versus performing the task demands concurrently, where specific task demands are interleaved. In the Dots task, for example. children homotygous for the Met/Met allele for the catcchol-Omethyltransferase genotype made more errors only in the mixed condition. relative to children homozygous for the $\mathrm{Val} / \mathrm{Val}$ allcle. suggesting that concurrent execution required more executive engagement (Diamond et al., 2004). Evidence for validity was supported if Condition $D$ performance, where children must both suppress responses and select response sets in the relevant context, differed from that of the average of the single-block conditions, $B$ and $C$.

Because exccutive control develops rapidly in preschoolers, these three theoretically derived, a priori condition comparisons were evaluated simultancously bcyond any background individual differences due to child age or sex, using hicrarchical linear modeling (SAS Proc Mixed, v8, maximum likelihood estimation). This approach offers several advantages over traditional analysis of variance, the most relevant of which is allowing the examination of the relative contribution of within and between-subject sources of variation in task perfornance. In these analyses, age was centered at 4.5 ycars (the sample mean age), and the Bonferroni corrcetion was applied to maintain fumilywise alpha, in which $\alpha_{\text {criticul }}=(.05 / 3)=$ .0125 for each planned comparison. Consistent with previous investigations, strong age-related performanç differences in latency were expected on the Shape School indexes, given the young age range sampled. Beçassc the Shape School is hypothesized to meusure executive skills comparably across the age range studied, condition-telated performance differences (Agc $\times$ Condition interactions) were not expected to vary with child age. Although young girls often demonstrate more advanced language skills than young boys do, most studies have not found sex-related executive performance differences in preschos)lers (e.g. Espy et al., 200I). Hence, such differences were not expected to be evident on the Shape School indexes, nor was Shape School condition performance expected to vary by sex.

Finally, the role of child vesabulary skills in Shape School performance was explored. Given the verbally ladcn, matcrial-spccific format of the Shape School, overall performance might vary by child vocabulary: furthermore, these differences in proficiency might be more cvident in the execulive conditions, related to facilitated automaticity and retrieval. In contrast to age and sex, which are static demographic covariates endemic to the child, vocabulary skills develop dynamically across age and are effects of interest. Therefore, these exploratory analyses were conducted by sequentially adding the effect of vocabulary io the existing models, which also included the age and sex covariates.

\section{Results}

First, Cronbach's alpha coefficients computed with the responses to each of the stimuli within each condition revealed adequate association in the executive conditions, Conditions $B$ $(\alpha=.71), \mathrm{C}(\alpha=.80)$, and D ( $\alpha=.74)$. In Condition A $(\alpha=.56)$, the coefficient likely was attenuated due to the high level of naming accuracy in this very simplc condition. Then, correlations among Shape School eondition-respective accuracies and latencies were calculated, with Table 2 showing the correlations within each dependent variable for each Shape School condition. Note the interclations among the respective accuracies from the cxecutive conditions, B, C, and D. Condition $A$ accuracy was not related to 
that of B, C, and D, although again, this correlation likely was attenuated due to low variability. In contrast, respective latencies were interrelated among all Shape School conditions. In Condition $A$, there was no relation between accuracy and latency $\left(r_{\mathrm{A}}=-.04\right.$, $\left.p_{\mathrm{A}}>.52\right)$, suggesting that deploying the simple stimulus-response rule did not require any trade-off in accuracy to achicve speeded naming. In contrast, there was evidence for such a trade-oft in Conditions $\mathrm{B}$ and $\mathrm{D}$, in which the number of correctly identificd stimuli and completion time were associated $\left(r_{\mathrm{B}}=-.18, p_{\mathrm{B}}<\right.$ $.01 ; r_{\mathrm{D}}=-.20, p_{\mathrm{D}}<.01$ ). It was interesting to note that there was a marginal relation between Condition $\mathrm{C}$ accuracy and latency $\left(r_{c}=12, p_{c}<.09\right)$, with children who named more stimuli correctly taking longer to complete the condition.

The relationships between Shape School performance and the criterion measures arc depicted in Table 3. Only Condition A performance was related to the Statue raw score, with children who were able to maintain the fixed "statue" position for longer durations taking less time to complete Shape School Condition A. VA random cat array performance was related to the respective Shape School Conditions B, C, and D latencies; those children who correctly identified more cats took less time to complete these conditions. After the cxperimenters controlled for Condition A baseline naming speed, the number of VA cats the children identified was still related to latency for Shape School Conditions B, $C$, and $\mathrm{D}\left(r_{B}=-0.22, p<.01 ; r_{C}=-.21, p<.01\right.$; and $r_{D}=-.26$, $p<.01)$. It is interesting that the number of cats cortectly iden. tified was also associated with Condition C accuracy. Not surprisingly, complction time of the VA random cat array was correlated with all the Shape School condition latencies. When bascline naming speed in Condition A was controlled, only the relation between the latency to complete the random VA cat array and Shape School Condition $C$ persisted $\left(r_{C}=.19, p<.02\right)$. The magnitude of the associations betwecn the respective Condition $A$, $B$, and $C$ latencies and the criterion messures did not differ by criterion measure, $F_{\mathrm{A}}(3,141)=0.15, p>93 ; F_{\mathrm{B}}(3,141)=1.24$, $p>.30 ; F_{C}(3,141)=1.16, p>33 ;$ nor by condition, $F_{\text {Digit sput }}$ $(3,181)=1.22, p>30 ; F_{\text {stutwe }}(3,162)=1.07, p>36 ; F_{\text {VA targets }}$ $(3,151)=1.36, p>.25 ;$ and $F_{V A \text { tlme }}(3,151)=0.14, p>93$. For Condition $\mathrm{D}$ latency, the correlation magnitudes differed margin-

Table 2

Correlations Among Shape School Variables by Condition

\begin{tabular}{lllll}
\hline Condition & A & B & C & D \\
\hline Stimuli correctly identified
\end{tabular}

\begin{tabular}{|c|c|c|c|c|}
\hline$\Lambda$ & 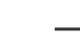 & & & \\
\hline B & -.03 & - & & \\
\hline C & .02 & $.30^{+\cdots-}$ & - & \\
\hline D & .01 & $.40^{*+1 *}$ & $.55^{* \alpha+\Delta}$ & - \\
\hline
\end{tabular}

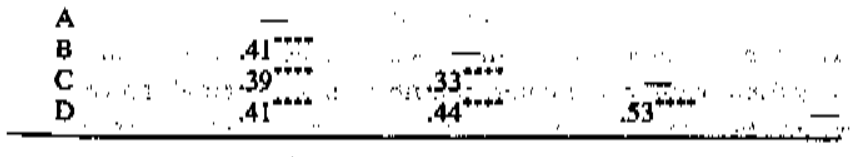

Note. $N=219$

$p<.0001$.
Table 3

Shape School Bivariate Correlations With Criterion Measures

\begin{tabular}{|c|c|c|c|c|}
\hline $\begin{array}{c}\text { Condition and } \\
\text { Shape School } \\
\text { index }\end{array}$ & $\begin{array}{l}\text { Digit } \\
\text { Span" }\end{array}$ & Statue" & $\begin{array}{l}\text { VA cat } \\
\text { targets }\end{array}$ & $\begin{array}{l}\text { VA cat } \\
\text { time }\end{array}$ \\
\hline \multicolumn{5}{|l|}{ A } \\
\hline Accuracy & -.01 & -.11 & -.04 & .05 \\
\hline Lutency & , (1) 6 & $.18^{\circ}$ & .12 & .15 \\
\hline \multicolumn{5}{|l|}{ B } \\
\hline Accuracy & .08 & .00 & .05 & .01 \\
\hline Latency & $.19^{-*}$ & .06 & $.25^{-*}$ & $.20^{\circ}$ \\
\hline \multicolumn{5}{|l|}{$\mathrm{C}$} \\
\hline Accuracy & $.26^{\prime \prime \cdots}$ & .07 & $.19^{\circ}$ & .06 \\
\hline Latency & $.15^{\circ}$ & .08 & $.24^{* *}$ & $.19^{\circ}$ \\
\hline \multicolumn{5}{|l|}{ D } \\
\hline Accuracy & .12 & .07 & .08 & .04 \\
\hline Latençy ${ }^{e}$ & .10 & .03 & $.29^{---}$ & $.17^{\circ}$ \\
\hline
\end{tabular}

Note. For magnitude comparisons, all variables were trunsformed to $z$ scores to render standard deviations on the same meuric. All time variables were multiplied by -1 . VA $=$ Visual Attention.

${ }^{2} N=185, M=3.81, S D=0.89,{ }^{\text {h }} N=166, M=22.38, S D=$ 7.59. ${ }^{\circ} N=155, M=17.74, S D=2.77$, ${ }^{\mathrm{d}} N=155, M=83.88, S D=$ 32.67. "Correlation magnitude varied by criterion measure, where correlation with the number of targets correctly identified on the Visual Attention car array was significantly greater $(p<.05)$ than that with \$tatuc. " $p<0.05,{ }^{* *} p=<.01,{ }^{* *} p=<.001 .{ }^{*-{ }_{p}}<.0001$.

ally by criterion measure, $F_{\mathrm{D}}(3,141)=2.54, p<.06$, where the correlation between Condition D latency and the number of VA cats correctly identified was larger than the respective correlation with Statue, $F_{D}(1,149)=7.49, p<.007$.

An unconditional means model revealed significant withinperson variation in Shapc School performance in both accuracy $\left(\sigma_{\mathrm{r}}{ }^{2}=0.51, S E=0.19, z=2.71, p<.01\right)$ and latency $\left(\sigma_{z}{ }^{2}=\right.$ 73.55, $S E=16.17, z=4.55, p<.0001)$. Bctwcen-person effects in accuracy $(M=13.38, S E=0.09), f(218)=146.73, p<.0001$, and latency $(M=35.84, S E=0.86), t(218)=41,79, p<.0001$. also were nonzero. In the conditional models that included the etfects of the child's age and sex covariates and those of the pertinent within-subject effect of condition, there was substantial within-person variation in accuracy $\left(\sigma_{0}{ }^{2}=1,01, S E=0.18, z=\right.$ $5.72, p<0001$ ). Although neither covariate was related to performance (both $p s>05$ ), Shape School accuracy differed as a function of condition, $F(3,645)=60.61, p<.0001$. Conditionrelated differences in accuracy, however, did not differ by child age, $F(3,645)=1.89, p>13 ; \operatorname{scx}, F(3,645)=1.23, p>.29 ;$ or the interaction of age and sex, $F(4,645)=0.14, p>.96$. Condition-rclated performance accounted for $41.87 \%$ of the individual variation in Shape School accuracy, on average. beyond that related to the covariates.' In like fashion, the inclusion of the within-subject condition term in addition to the child age and sex covariates resulted in significant within-person variation in latency $\left(\sigma_{0}{ }^{2}=105.90, S E=14.90, z=7.11, p<.0001\right)$. As with accu-

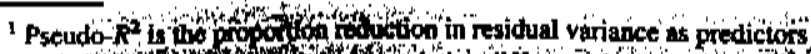

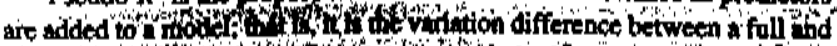

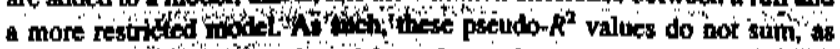

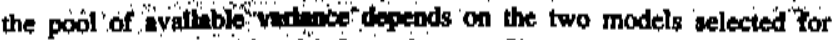
comparison. For idditional information, see Singer and Willett (2003).
} 
racy, Shape School latency differed by condition, $F(3,645)=$ $196.63, p<10001 ;$ although these condition-related latency differences did not vary by child a $\mathrm{gC}, F(3 ; 645)=1.63, p>18$; sex, $F(3,645)=0,41, p>74$, or the inieraction of age and sex, $F(4$. $645)=0.52, p>71$, Condition-related latency accounted for 47.15\% (see Footnote 1) of individual performance variation above that of the covariates. Furthermore, as hypothesized, the child's age was related to Shape School latency $(\gamma=-7.32, S E=$ 2.85), $t(645)=-2.57, p<01$, whereas sex was not $(\gamma=-0.11$, $S E=2.78), t(645)=-0.04, p>97$. In both of these models, the significant main effect of the condition provides the basis to further pursue evjdence for validity by examining the a priori condition contrasts.

In the first a priori contrast examining sensitivity to cxeculive demands, both accuracy, $r(645)=9.78, p<,(001$, and latency, $t(645)=11.58, p<.0001$, differed between the executive (average of Conditions B, C, and D) and control (Condition A) conditions, consistent with our hypothesis. Young children named nearly all of the control Condition $\Lambda$ stimuli correctly, on averagc $(M=14.93$ stimuli, $S E=0.14), r(645)=109.64, p<,(0(0) 1$. The "cost" on naming accuracy of the added executive demands across Conditions B, C, and D was -2.10 stimuli $(S E=0.21), t(645)=$ $-9.78, p<.0001$, resulting in an expected value of 12.82 stimuli correctly named across executive conditions. A similar pattem was evident for latency, where the expected completion time was 22.78 s $(S E=1,15), r(645)=19.76, p<.0001$, with a cost of an additional $19.37 \mathrm{~s}(S E=1.67)$ across the executive conditions, $t(645)=11.58, p<.0001$.

Consistent with prediction, a similar pattern was cvident for both accuracy and latency in the second contrast comparing Shape School performance by inhibitory processing demands, namely, comparing response suppression in Condition $\mathrm{B}$ and context. controlled sclection in Condition C. Young children, on average, named 14.34 stimuli $(S E=0.14)$ correctly in Condition B, r(1, $645)=105.34, p<0001$. The difference in naming accuracy as a function of inhibitory demands was -2.25 stimuli ( $S E=0.26$ ). $t(1,645)=-8.55, p<.0001$. Accuracy on Condition C stimuli was estimated to be 11.98 stimuli correctly named $(S E=0.14)$. $t(1,645)=88.01, p<.0001$. A comparable pattern was observed for latency, where the cstimated completion time was $26.76 \mathrm{~s}$ in Condition B $(S E=1.15), r(1,645)=23.21, p<.0001$. The difference in latency between the two inhibitory conditions, on average, was $20.93 \mathrm{~s}(S E=2.05), t(1,645)=10.22, p<.0001$. The expected Condition $C$ latency was 47.41 s for Condition $C$ $(S E=1.15), \ell(1,645)=41.12, p<.0001$.

Finally, in the a priori comparison examining the cost of performing concurrent executive processing in Condition $D$ versus the single, blocked executive demands in Conditions $\mathrm{B}$ and $\mathrm{C}$, the same pattem was evident for both accuracy and latency, as we hypothesized. The difference in accuracy on average across Conditions $B$ and $C$ was $0.83(S E=0.23), t(1,645)=3.63 . p<.0003$, lower than on Condition D, in which young children were estimated to name an average of 12.26 stimuli correctly $(S E=.14)$, $t(1,645)=90.08, p<.0001$, Similarly, for latency, the expected value for the single-block conditions was $20.93 \mathrm{~s}$ more ( $S E=$ 2.05), $t(1,645)=10.22, p<.0001$, than for the concurrent condition, Condition D, in which children took an estimated 46.42 $s(S E=1,15)$ to complete the conçurrent condition, $t(1,645)=$ 40.27, $p<.0001$.

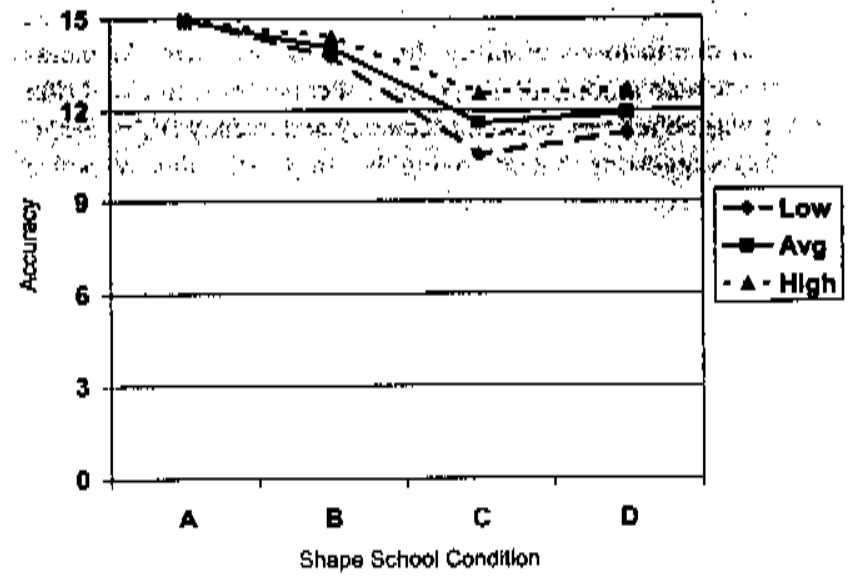

Figure 1. Shape School accuracy as a function of condition type and vocabulary level (Low $=85$ : Average $($ Avg $)=100 ;$ High $=115)$.

To explore the role of child vocabulary, we reran the same models, including a main effect of child vocabulary and an interaction of vocabulary with condition type for both accuracy and latency-dependent variables. Only for Shape School accuracy did the effect of condition type vary by vocabulary, $F(1,630)=9.86$, $p<.0001$, in addition to a significant main effect of vocabulary level $(\gamma=.72, S E=.16), r(1,630)=4.48, p<.0001$. These results are depicted in Figure 1. There was little difference in Condition $A$ accuracy between children of higher (standard score = 115), middle (standard score $=100$ ), and lower (standard score $=85$ ) vocabulary levels. There was a moderate difference in accuracy in Condition $B$ among children of varying levels of vocabulary. There was a substantial difference in accuracy on Condition $\mathrm{C}$ among children of varying vocabulary lcvels. It is interesting that accuracy on Condition D related to vocabulary level was attenuated relative to Condition $\mathrm{C}$ but was more substantial than Condition B. Although the vocabulary-related effects were significant, they accounted for only $3.47 \%$ (sec Footnote 1) of the variance in Shape School accuracy beyond the effects of the covariates and condition type. In contrast to accuracy, only the main effect of vocubulary was significant, $t(1,630)=-2.88, p<$ .0041 , with children who had higher vocabulary scores completing the conditions faster by an average of -3.97 s $(S E=1.38)$ independent of condition type, $F(3,630)=0.69, p>.55$.

\section{Discussion}

Our purpose for this article was to investigate the cvidence for validity for the Shape School (Espy, 1997), a novel test of executive control recently deverloped for preschool children, First, the Shape School items were associated adequately, demonstrated by acceptable Cronbach's alpha values for each condition and the consistent interrelations among condition accuracies and latencics. Note, however, that a substantive relation among latencies across conditions is expected, even in very young preschool children. consistent with a common contribution of general processing speed. Furthermore, Shape School performance was related to performance on other commercially available tests that purport to measure executive control. Generally, nonzero relations to crite- 
rion measures werc most evident for Shape School latencies, although the magnitude of the criterion associations did not differ by condition. Not surprisingly, latency measurcs better reflected intersubject variability, given the high degree of naming accuracy under thesc simple stimulus -response mappings. Also, Shape School condition latency relations with Digit Span and both VA indexes were nonzero in contrast to those with \$tatuc, although the magnitude of the correlations did nor differ statistically by criterion measure. Thesc findings provide good evidence for validity. although future investigations should include a wide range of critcrion measures, including experimental exeçutive tasks and tasks that are not expected to be related to Shape School performance, in order to assess discriminant validity.

These findings also shed some light on the processes that might subserve Shape School performance. VA is considered to be a selective-sustained attention task, whereas Digit Span is typically vicwed as assessing short-tcrm memory span. Faster identification of the relevant features that distinguish figures, as evidenced on VA, would also facilitate Shape School performance. The ability to hold more information in mind, measured by maximal digit span, would enable more proficient Shape School performance, pcrhaps by more efficient maintenance of relevant stimulusresponse mappings. These findings fit within the rubric of the interplay between working memory and attention deployment (e.g., Cowan, 1995: Kane, Bleckley, Conway, \& Engle, 2001) and the overlap with executive control, more broadly (e,g., Kastner \& Ungerleider, 20(K); Posncr \& Peterson, 1990). These interrclations likely are developmentally dynamic and will require longitudinal. multimethod investigations for a more full characterization.

It is significant that Shape School performance varied among conditions contrasted to reflect cxecutive demand differences, a fact that provides cogent evidençe for task validity, First, the basic distinction between the baseline control and executive conditions was supported. This distinction is important, providing a sound basis for future use of developmental cognitive ncuroscience methods that isolate relative cognitive "costs," whereby baselinc cognitive processes, in this casc naming speed, arc removed either statistically or through simple subtraction. Moreover, there was a clear distinction between performance on Conditions $B$ and $C$, hypothesized to reflect differing inhibitory processes, response suppression, and contcxt-controlled selection among competing stimulus-response rules. Likely contributing to the observed sensitivity in these contrasts is the general comparability between thesc two Shape School conditions in other demands, including comparable proactive interference (where the target of the "inhibition" is previously relevant information). The working memory load was considered comparable to those in Conditions $B$ and $C$, although retaining a stimulus-response mapping for a suppressed response might not rcquire the same memory resources as retaining a mapping with an elicited response. In light of Friedman and Miyake's (2004) distinction between inhibitory processes that control proactive interference from competing rules and distraction from irrelevant information, both Conditions $B$ and $C$ also are comparable in proactive interference and in the level of distruction provided by the surrounding stimuli in the storyook dray. Note,

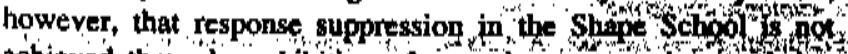
achicyed through prohibition of somatic motor actions, and that Condition B performance and Statue were not related Inhibition of somatic motor actions might reflect a precursor to the types of inhibition considered here (Carlson \& Moses, 2001). In future studics, further support for separablc inhibitory skills could bc established through unique relations to other cognitive or behavior outcomes (c.g. Bull \& Seerif, 2001) or through distinct patterns of relative impairmenls in young children who have specific clinical disorders,

Evidence for validity was also provided through the demonstrated sensitivity to complexity level. There was a clear cost in performance, both in accuracy and latency, presumably through the additional cognitive resources nccessary in the concurrent Condition D, relative to the single-block conditions, $\mathrm{B}$ and $\mathrm{C}$. This effect is even more dramatic considering that in Condition $\mathrm{D}$, the child has to namc only eight stimuli-fewer than in either Condition B or C. Halford, Andrews, and Jensen (2002) have theorized that exccutive control is engaged precisely in response to complexity, although it remains less than clear how to opcrationalize complexity, whether at the lcvel of the stimulus, response, or rule, and/or at processing levels. Concurrent processing demands inevitably makc grcater demands on memory; thereforc, the increased time may reflect lime to access long-term retrieval and memory stores (Munakata, Morton, \& Yerys, 2003). In Condition D, children might need to rellect more upon the relcvant stimulusresponse mapping rulc as they select and implement, given that the different relcvant stimulus featurcs are interspersed in the concurrent condition (Zelazo et al., 2003). Finally, there are more proactive stimulus features than were previously relevant, providing grcater attentional pull; theretore, more inhibitory resources are demanded to resist this attentional inertia (Kirkham et al., 2003).

Of note was the lack of condition-related differences that varied with agc or sex. These findings indicate that condition-related Shape School performance is not variable among older or younger preschoolers, girls or boys, and they support comparable sensitivity across the full preschool age range in both sexes. Not surprisingly, there were agc-related main effcct difterences in naming speed in the latter two comparisons, presumably reflecting the samc age-dependent increases in processing speed that underlie the intercorrelations among the condition latencies. Finally, Shape School performance differed somewhat among children who had varying vocabularics. First, independent of condition type, latencies generally were shorter in children who had higher vocabularics, suggesting facilitated retrieval of verbal information that resulted in more efficicnt speeded naming. Second, naming accuracy in the different Shape School conditions varied with the child's vocubulary level, as was particularly cvident on Condition $\mathrm{C}$ relative to Condition B or D. Keeping in mind the caveat that two differing vocabulary measures werc administered here, because the Shape \$chool is a verbal naming task and vocabulary is the most reliable and stable index of general intelligence (Sattler, 1992), greater verbal proficiency appcars to differentially facilitate accuracy in those conditions that require context-controlled selection. It is interesting that this relationship somewhat parallels the impor. tant role of fluid intelligence in executive control in adults (Duncan et al., 2000; Gray, Chabris, \& Braver, 2003; Kane \& Engle, 2002). Administering a more comprehensive intelligence measure to preschol childiren would properly address this issue.

The utility of the Shape School as a measure of executive control in preschool children was supported, with good evidepce for validity demonstrated by multiple methods. A next step is to determine whether the Shape School is sensitive in children who 
have clinical disorders and whether unique profiles are evident in chifien who have different disorders Another possibility is to

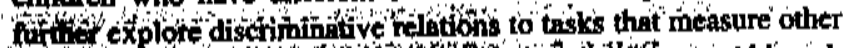

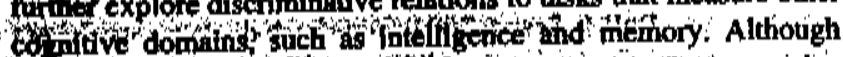

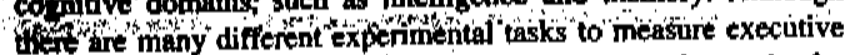
control in this age range, there are comparatively few tasks for which the psychometric properties have been explored (e.g., Espy \& Cwik, 2004), a critical endeavor prior to application in the clinical context. Also, longitudinal investigations are sorely nceded to (a) better map the dynamic proccss of the development of executive control and later exceutive abilitics at school agc and (b) determine the utility of the Shape School as an index of this unfolding process.

Certainly, there is more work to be done to improve the task parameters. First, minor changes, such as increasing the number of items in Condition D, might improve the detection of the cost of complexity. In addition, given the distinction between proactive interference and distraction noted by Friedman and Miyake (2004), the impact of the type of distraction could be manipulated by varying the presentation format to include single stimulus presentation, in addition to the storybook stimulus array. Although the proactive interference of the specific stimulus-response mappings is developed by the story line, the greater natural context available for the child to draw upon to execute the relevant response when the facial expression cues suppression and the hat cues another naming dimension might have influenced performance; this possibility could be manipulated fritfully. Finally, it would be useful to constrain stimulus order to allow researchers to manipulate inhibitory load by systcmatically varying the number of stimuli that precede the inhibitory stimulus target. Such a change to both Conditions B and C might lend further support to the distinction betwcen the demands for response suppression and contextcontrolled selection, for example, if the manipulation differentially affected pertormance. These issues notwithstanding, the Shape School offers polential as a tool to measurc executive control in this challenging agc range.

\section{References}

Allport, A., Styles, E., A., \& Hsieh, S. (1994), Shifting intertional sct: Exploring the dynamic control of tasks. In C. Umilta M. Moscovitch (Eds.), Aterntion and performance XV: Conscioss and noncontcious information processing (pp, 421-452). Cumbridgc, MA: MIT Press.

Anderson, V, (1998). Assessing executive functions in children: Biological, psychologicul, and developmental considerations. N'uropsycholog. ical Rehahilitation, 8, 319-349.

Anderson, V., Anderson, P., Grimwood, K. \& Nolan, T. (2004), Cognitive and executive functions 12 yeurs after childhood bacterial meningitis: Effect of acule neurologic complications and age of onsct. Journal of Pediatric Puycholog, 29, 67-82.

Barch, D., Braver, T., Ny'strom, L., Forman, S., Noll, D., \& Cohen, J. (1997). Dissociating working memory from task difficulty in human prefrontal cortex. Neuropsychologia. 35, 1373-1380.

Bishop, D. V. M., Aamodt-Lcaper, G., Creswell, C., McGurk, R.. \& Skuse. D. (2(X)1). Individual differences in cognitive planning on the Tuwer of Hanoi task: Neuropsychological malurity or measurement error? Joumal of Child Psychology and Psychiatri, 42, 551-556.

Brooks, P., Hanaver, J., Padowska, B., \& Rosman, H. (2003). The role of selective attention in preschoolers" nulc usc in a novel dimensional card sort. Cogntinive Development, 18, 195-215.

Bull, R., Johnston, R., \& Roy, J. (1999). Exploring the roles of the visual-spatial gketch pad and central executive in children's arithmetical tills: Views from cognition and developmental neoripsychology. $D e$ Suepepinental Neuropsychology, 15, 421-442.

Bull, $R_{;}$\& Scerif, $Q$, (2001). Executive functioning is a predictor of children's mathematics ubility: Inhibition, switching, and working memory, Developmental Neuropsychology, 19. 273-293.

Carlson, S., \& Moses, L. (2001). Individual differences in inhibitory control and children's theory of the mind. Child Development, 72, $1032-1053$.

Cascy, B. J., Forman, S., Franzen, P., Berkowitz, A., Braver, T., Nystrom, L., et al. (2001). Sensitivity of prefrontal cortex to changes in target probability: A functional MRI study. Human Brain Mapping, 13, 26-33.

Cowan, N. (1995), Attention and memory: An integrated framework. New York: Oxford University Press.

Desimone, R.. Duncun, J. (1995), Neural mechanisms of selective visual attention. Annual Review of Neuroscience, 18, 193-222.

Diamond, A., Briand, L.., Fossella, J., \& Gehlbach, L. (2004). Genetic and neurochenical modulation of prefrontal cognitive functions in children. American Joumal of Psychiatry, 161, 125-132.

Diamond, A., Kirkham, N., \& Amso, D. (2002). Conditions under which young children cun hold two rules in mind and inhibit a pre-potent response. Developmental Psychology. 38. 352-362.

Diamond, A., Prevor, M., Cullender, G., \& Druin, D. (1997). Prefrontal contex cognitive deficits in children treated early and continuously for PKU. Monographs of the Society for Research in Child Development, 62, 1-208.

Diamond, A., Taylor, C. (1996). Development of an aspect of executive control: Development of the abjlities to remember what 1 said and to "Do as I say, not as I do." Detrelopmental Psychobiology. 20. 315-334.

Duncan, J., Seitz, R. J., Kolodny, J., Bur, D., Herrog, H., Ahmed, A., et al. (2000, July 21). A neural basis for general intelligence. Science, $28 \%$, $457-460$.

Elliot, C. D. (1990). Differential ability scales. San Antonio, TX: The Psychological Corporation.

Espy, K. A. (1997), The Shape School: Assessing executive function in preschool children. Developmental Neuropsychology, 13, 495-499.

Espy, K. A., Cwik, M. (2004), The development of a trail making test in young children: The TRALSP. The Clinical Neuropsychologist, I8, $411-422$.

Espy, K. A., Kaufmann, P., \& Glisky, M. (1999). Neuropsychological function in toddlers exposed to cocaine in utero: A preliminary study. Developmental Neuropsychology, 15, 447-460.

Espy, K. A., Kaufmann, P., Glisky, M., \& McDiarmid, M. (2001). New procedures to assess executive functions in preschool children. Clinical Neuropsychologist, 15, 46-58.

Espy, K, A., Kaufmann, P., McDiarmid, M, \& Glisky, M. (1999), Executive functioning in preschool children: Performance on A-not-B and other dclayed response format tusks. Brain and Cognition, 41, 178-199.

Espy, K. A., MçDiarmid, M., Cwik. M., Senn, T., Hamby, A.، \& Stalets. M. (2004). The contribution of executive functions to emergent mathematic skills in preschool children. Developmental Neuropsychology, 26, 456-465.

Espy, K. A., Stalets, M., McDiarmid, M., Senn, T., Cwik, M., \& Humby, A. (2002). Exçcutive functions in preschool children bom preterm: Application of cognitive neuroscience paradigms. Child Neuropsychology, 8, 83-92.

Ewing-Cobbs, L., Prasad, M., Landry, \$., Krumer, L., \& DeLeon, R. (2004). Executive functions following traumutic brain injury in young children: Impaiment in working memory, Developmental Neuropsy. chology, 26. 487-5I2.

Friedman, N.. Miyake, A. (2004). The relations among inhibition and interference control funcrions: A latent-variable analysis. Journal of Experimental Psycholoxy: General, 133, 101-135.

Gathercole, S., \& Pickering. S. (2000). Working memory deficits in chil- 
dren with low achievements in the national curriculum at 7 years of age. British Journal of Educational Psychology, 70, 177-194.

Gerstadt, C., Hong. Y., \& Diamond, A. (1994). The relation between cognition and action: Performance of 3.5- to 7-year-olds on Stroop-like Day-Night test. Cognition, 53, 129-153.

Gray, J., Chabris, C., \& Braver, T. (2003). Neural mechanisms of genera] fluid intelligence. Nanure Neuroscience, 6, 316-322.

Halforu, G. Andrews, G., Jensen, I. (2002). Integration of category induction and hierarchical classification: One paradigm at two levels of complexiry. Journal of Cognition \& Development. 3, 14,3-177.

Hughes, C. (1998a). Executive function in preschoolers: Links with theory of mind and verbal ability. British Journal of Developmental Psychol. ogy, 16, 233-253.

Hughes, C. (1998b). Finding your marbles: Does preschoolers' surategic behavior predict later understanding of mind? Developmental Psychol. ogy, 34, 1326-1339.

Hughes, C., White, A, Sharpen, J., Dunn, J. (2000). "Hard-to-manage" preschoolers" pecr problems and possible cognitive influences. Journal of Child Psychology art Psychiatry, 4I, 169-179.

Isquith, P., Gioia, G., \& Espy, K. (2004). Executive function in preschool children: Examination through everyday bchavior. Developmentul Neuropsychology, I8, 403-422.

Kane, M., Blecklcy, M., Conway, A., Engle, R. (2001). A controlledattention view of working-memory capacity. Joumal of Experimental Psychology: General, 130, 169-183.

Kane, M., \& Engle, R. (2002). The role of the prefrontal cortex in working memory capacity, executive attcntion, and general fluid intelligence: An individual differences perspective. Psychonomic Bullerin \& Review, 9, 637-671.

Kastner, S., \& Ungerleider, L. G. (2000). Mechanisms of visual attention in the human cortex. Annuul Review of Neuroscience, 23, 315-341.

Kirkham, N. Cruess, L., \& Diamond, A. (2003). Helping children apply their knowledge to their bchavior on a dimension-switching task, Developmental Science, 6, 449-467.

Kochanska, G., Murray, K., Jacques, T., Kocnig. A., \& Vandegeesi, K. (1996). Inhibitory control in young children and its role in emerging internalization. Child Development, 67, 490-507.

Korkman, M., Kirk, U, \& Kemp, S. (1998). NEPSY; A developmental neuropsychological assessment manual. Sun Antonio, TX: The Psychological Corporation.

Levin, H., Fletcher, J., Kufera, S., Harward, H., Lilly, M., Mendelsohn, D., et al. (1996). Dimensions of cognition measured by the Tower of L.ondon and other cognitive tasks in hęad-injured children and adolcscents. Developmental Neuropsychology. 12, 17-34.

Miller. E. (2000). The prefrontal cortex \& cognitive control. Nature' Newroscience, 1, 59-65.

Miller, E., \& Cohen, J. (2001). An integrative theory of prefrontul cortex funçtion. Annual Review of Neruroscience, 24, 167-202.
Munakata, Y, Morton, J., \& Yerys, B. (2003), Children's perseveration: Attentional inertig und altemative accounts. Developmental Science, 6 . 47I-476.

Nigg, J, T, (2000). On inhibition/disinhibition in developmental psychopathology: View from cognitive and personality psychology and a working inhibition taxonomy, Psycholngical Bulletin, 126, 220-246.

O'Reilly, R., Noelle, D., Braver, T., Cohen, J, D. (2002). Prefrontal cortex and dynamic categorization tasks; Representational organization and neuromodulatory control. Cerebral Cortex, 12, 246-257.

Pennington, B., \& Ozonoff, S. (1996). Exxecutive funçtion \& developmental psychopathology. Journal of Child Psychology \& Psychiatry \& Allied Disciplines, 37, 51-87.

Pemer, J., \& Lang, B. (2002). What causes 3-year-olds difficulty on the Dimensional Change Card Sorting takk? Infant and Child Development, 11. 93-105.

Posner, M., \& Petersen, S. (1990). The attention system of the human brain. Annual Review of Neuroscience, 13, 25-42.

Rced, M., Pien, D., \& Rothbart, M. K. (1984). Inhibitory self-control in pre-school children. Merrill.Palmer Quarterly. 30, 131-147.

Rennie, D. A. C., Bull, R, \& Diamond, A. (2004). Executive functioning in preschoolers: Reducing the inhibitory demunds of the Dimensional Change Curd Sort task. Developmental Neuropsychology, 26, 423-443.

Sattler, J. M. (1992). Assessment of children (3"' ed.). San Dicgo, CA: Jerome M. Sattler.

Singer, J., \& Willett, J. (2003). Applied longitudinal data analysis; Modcling change and event occursence. New York: Oxford.

Wcchsler, D. (1990). Wechsler Preschool and Primary Scale of Intelligence-Revised. San Antonio, 'TX: The Psychological Corporation.

Welsh, M., Pennington, B., \& Groisser, D. (1991). A normativedevelopmental study of executive function: A window on prefrontal function in children. Developmental Neuropsychology, 7, 131-149.

Woodcock, R. \& Johnson, M. (1989). Woodcock-Johnson PsychoEducationul Bantery-Revised. Allen, TX: DLM Teaching Resourçes.

Wright, I., Waterman, M., Prescott, H., \& Murdoch-Eaton, D. (2003). A new Stroop-like measure of inhibitory function development: Typical developmental trends. Journal of Child Psychology \& Psychiatry, 44, 561-575.

Zelazo, P., Fryc, D., \& Rapus, T. (1996). An age-related dissociation between knowing nules and using thern. Cognitive Development, $I I$. $37-63$.

Zelazo, P., Mueller, U., Frye, D., \& Marcovitch, S. (2003). The development of executive function in childhood. Monographs of the Society for Research in Child Development, 68(3. Serial No. 274).

Reccived June 3, 2004

Revision received April 26, 2006 Accepted April 27, 2006 